\title{
FAKTOR YANG BERHUBUNGAN DENGAN PERSONAL HYGIENE PADA REMAJA PUTRI DI SMA NEGERI 1 KOTAMOBAGU
}

\author{
Hairil Akbar \\ Prodi Kesehatan Masyarakat STIKES GrahaMedika, Kotamobagu
}

\begin{abstract}
Background: Adolescent girls are vulnerable to reproductive organ infections due to a lack of personal hygiene. Personal hygiene is an effort to maintain one's personal health with the purpose to prevent the occurrence of diseases and to improve health status. Problems that will arise due to lack of hygiene of the reproductive organs, namely some venereal diseases such as cervical cancer, vaginal discharge, genital skin irritation, allergies, and inflammation or urinary tract infections. Objective: The purpose of this study was to analyze factors related to personal hygiene. Method:This study applied observational analytic study with cross-sectional study approach and a sample of 100 female adolescents using a questionnaire. The sampling technique used simple random sampling and data analysis was done using the chi-square test. Result: The results of the analysis obtained knowledge ( $p$-value $=0003)$ and socioeconomic status ( $p$-value $=0,000)$. Conclusion: Therefore it can be inferred that knowledge and socioeconomic status were factors associated with personal hygiene in the female adolescents.
\end{abstract}

Keywords: Knowledge, Personal hygiene, Socio-economic status

\section{PENDAHULUAN}

Masalah kesehatan sangat kompleks dan saling berkaitan dengan masalah-masalah di luar masalah kesehatan itu sendiri demikian pula untuk mengatasi masalah kesehatan masyarakat tidak hanya dilihat dari segi kesehatan itu sendiri tapi harus dari seluruh segi yang ada pengaruhny terhadap kesehatan tersebut (Notoatmodjo, 2011). Dalam kehidupan seharihari kerbersihan merupakan hal yang sangat penting dan harus diperhatikan karena kebersihan akan memengaruhi kesehatan, kenyamanan, keamanan dan kesejahteraan klien.

Masa remaja berawal saat usia 12 sampai dengan 24 tahun. Peraturan Menteri Kesehatan RI Nomor 25 Tahun 2014 menjelaskan remaja adalah penduduk dalam rentang usia 10-18 tahun. Sedangkan menurut BKKBN, 10-24 tahun tergolong usia remaja dengan status belum melakukan pernikahan (Katarina Canggih Pythagoras, 2017). Perilaku atau kebiasaan seseorang dalam menjalankan kehidupan sehari-hari berkaitan dengan kebersihan (personal hygiene) yang juga dapat mempengaruhi kesehatan (Lavenia \& Dyasti, 2019). Praktik hygiene seseorang dipengaruhi oleh factor pribadi, social budaya. Jika seseorang sakit, biasanya masalah kebersihan kurang diperhatikan Mayoritas persoalan yang dihadapi para remaja adalah persoalan kesehatan reproduksi(Wahyudi et al., 2018).

Personal hygiene adalah suatu tindakan untuk memelihara kebersihan dan kesehatan seseorang untuk kesejahteraan, baik fisik maupun psikisnya. Perawatan kesehatan dan kebersihan adalah hal yang banyak dibicarakan dalam masyarakat. Kebiasaan menjaga kebersihan, termasuk kebersihan organ-organ seksual atau reproduksi merupakan awal dari menjaga kebersihan (Isro'in Laily., 2011). Masalah yang akan timbul akibat kebersihan organ reproduksi yang kurang baik yaitu timbul beberapa penyakit kelamin seperti kanker seviks, keputihan, iritasi kulit genital, alergi, peradangan atau infeksi saluran kemih. Hal tersebut berkaitan dengan saluran kemih dibawah wanita lebih pendek, sehingga dapat dengan mudah terpapar kuman dan bibit 
penyakit. Kuman tertentu dan jumlah tertentu dapat menimbulkan peradangan dan dapat menimbulkan rasa sakit. Maka dari itu sangat penting untuk menjaga kebersihan vagina agar mencegah kuman-kuman tersebut masuk kedalam alat kelamin dan saluran kencing wanita (Nadesul, 2008). Perempuan menghadapi tantangan yang lebih besar dari pada laki-laki dalam mengakses air, sanitasi, dan kebersihan dalam pemenuhan kebutuhan sehari-hari mereka. Kondisiinidiperberatdenganrendahnya personal hygiene yang meningkatkan risiko infeksi saluran reproduksi (ISR). Peningkatan kasus ISR dilaporkan terjadi pada 3.952 gadis dan wanita dari dua distrik pedesaan di India tahun 2016 (Baker et al., 2017).

Penelitian yang dilakukan di Asia Selatan, di daerah Bengal Selatan tentang tingkat pengetahuan kebersihan organ reproduksi dari 160 anak perempuan didapatkan $67,5 \%$ pengetahuan baik, sedangkan $32,5 \%$ tidak memiliki pengetahuan tentang kebersihan organ reproduksi. Data keputihan tentang kesehatan reproduksi menunjukkan bahwa $75 \%$ wanita di dunia mengalami keputihan paling tidak sekali seumur hidup dan $45 \%$ diantaranya mengalami keputihan sebanyak 2 kali atau lebih. Di Indonesia kejadian keputihan semakin meningkat (Atsani, 2012). Hasil penelitian (Pamaruntuan et al., 2014), yang dilakukan di SMA Negeri 4 Manado didapatkan bahwa responden dengan hygiene perorangan yang baik tentang daerah kewanitaan sebesar 150 responden $(74,3 \%)$ dan yang memiliki pengetahuan yang kurang baik tentang hygiene perorangan sebesar 52 responden $(24,7 \%)$. Penelitian ini sejalan dengan penelitian (Tulus et al., 2014), di SMA Kristen 1 Tomohon yaitu sebanyak $62(96,9 \%)$ orang berpengetahuan baik tentang hygiene perorangan dan $2(3,1 \%)$ orang berpengetahuan sedang.

Berdasarkan hasil survei yang dilakukan pada remaja responden di SMA Negeri 1 Kotamobagu bahwa mereka masih kurang pengetahuannya mengenai personal hygiene sehingga tujuan dari penelitian ini menganalisis faktor yang berhubungan dengan personal hygiene remaja responden di SMA Negeri 1 Kotamobagu.

\section{METODE}

\section{JenisPenelitian}

Jenis penelitian ini adalah observasional analitik dengan desain cross sectiona study.

\section{Lokasi dan Waktu Penelitian}

Penelitian dilaksanakan di SMA Negeri 1

Kotamobagu pada bulan Februari tahun 2020.

\section{Populasi dan Sampel}

Populasi dalam penelitian ini yaitu seluruh remaja putri yang bersekolah di SMA Negeri 1 Kotamobagu sebanyak 719 siswi. Jumlah sampel penelitian sebanyak 100 siswi dengan pengambilan sampel menggunakan Simple random sampling.

\section{Pengumpulan Data}

Pengumpulan data dilakukan dengan menggunakan kuesioner yang disedikan, terstruktur, dan telah diuji validitas dan reabilitasnya.

\section{Pengolahan dan Analisis Data}

Pengolahan data dilakukan dengan komputer menggunakan statistik deskriptif dan statistic inferensial non parametrik. Tahap pengolahan data berupa penyuntingan data (editing), pengkodeandata (coding) dan memasukkan data (entri data). Analisis inferensial yang digunakan pada penelitian ini yaitu uji Chi-square.

\section{HASIL}

Analisis Univariat

Pengetahuan

Tabel 1 Distribusi responden berdasarkan pengetahuan

\begin{tabular}{lcc}
\hline Pengetahuan & Frekuensi & \% \\
\hline Baik & 43 & $43,0 \%$ \\
Kurang baik & 57 & $57,0 \%$ \\
$\quad$ Total & 100 & $100 \%$ \\
\hline
\end{tabular}

Menunjukkan bahwa distribusi frekuensi berdasarkan pengetahuan terbanyak pada pengetahuan kurang baik yaitu sebanyak 57 responden $(57,0 \%)$. Sedangkan yang terendah pada pengetahuan baik yaitu sebanyak 38 responden $(38,0 \%)$. 
Status SosialEkonomi

Tabel 2 Distribusi responden berdasarkan status social ekonomi

\begin{tabular}{ccc}
\hline $\begin{array}{c}\text { Status } \\
\text { Sosial } \\
\text { Ekonomi }\end{array}$ & Frekuensi & $\%$ \\
\hline Cukup & 47 & $47,0 \%$ \\
Kurang & 53 & $53,0 \%$ \\
Total & 100 & $100 \%$ \\
\hline
\end{tabular}

Menunjukkan bahwa distribusi frekuensi berdasarkan status social ekonomi terbanyak pada status social ekonomi kurang yaitu sebanyak 53 responden $(53,0 \%)$. Sedangkan yang terendah pada status social ekonomi cukup yaitu sebanyak 47 responden $(47,0 \%)$

\section{Analisis Bivariat}

Analisis bivariat dalam penelitian ini bertujuan untuk mengetahui hubungan pengetahuan dan status social ekonomi dengan personal hygiene.

Tabel 3. Hasil Akhir Analisis Bivariat

\begin{tabular}{|c|c|c|c|c|c|c|c|c|}
\hline \multirow{3}{*}{ VariabelIndependen } & \multicolumn{4}{|c|}{ Personal Hygiene } & \multirow{2}{*}{\multicolumn{2}{|c|}{ Total }} & \multirow{3}{*}{\multicolumn{2}{|c|}{$\begin{array}{l}\text { OR } \\
(95 \% \\
\text { CI })\end{array}$}} \\
\hline & \multicolumn{2}{|c|}{ Baik } & \multicolumn{2}{|c|}{ KurangBaik } & & & & \\
\hline & $\mathbf{n}$ & $\%$ & $\mathbf{n}$ & $\%$ & $\mathbf{N}$ & $\%$ & & \\
\hline \multicolumn{9}{|l|}{ Pengetahuan } \\
\hline Baik & 25 & 65,8 & 13 & 34,2 & 38 & 100 & \multirow{3}{*}{$\begin{array}{c}3,497 \\
1,5-8,2\end{array}$} & \multirow{3}{*}{0,003} \\
\hline Kurangbaik & 22 & 35,5 & 40 & 64,5 & 62 & 100 & & \\
\hline Jumlah & 47 & 47,0 & 53 & 53,0 & 100 & 100 & & \\
\hline \multicolumn{9}{|l|}{ Status Sosial } \\
\hline Ekonomi & & & & & & & \multirow{4}{*}{$\begin{array}{c}6,620 \\
2,7-15,9\end{array}$} & \multirow{4}{*}{0,000} \\
\hline Cukup & 31 & 72,1 & 12 & 27,9 & 43 & 100 & & \\
\hline Kurang & 16 & 28,1 & 41 & 71,9 & 57 & 100 & & \\
\hline Jumlah & 47 & 47,0 & 53 & 53,0 & 100 & 100 & & \\
\hline \multicolumn{4}{|c|}{$\begin{array}{l}\text { Menunjukkan bahwa responden } \\
\text { dengan pengetahuan baik dan memiliki } \\
\text { personal hygiene baik sebanyak } 25 \\
\text { responden }(65,8 \%) \text {, dan yang memiliki } \\
\text { personal hygiene kurang baik sebanyak } 13 \\
\text { responden }(34,2 \%) \text {, sedangkan responden } \\
\text { dengan pengetahuan kurang baik dan } \\
\text { memiliki personal hygiene baik yaitu } \\
\text { sebanyak } 22 \text { responden }(35,5 \%) \text {, dan yang } \\
\text { memiliki personal hygiene kurang baik } \\
\text { yaitu sebanyak } 40 \text { responden }(64,5 \%) \text {. } \\
\text { Berdasarkan dari hasil uji Chi-square } \\
\text { dengan } \rho \text { value }=0,003 \text { ( } \rho \text { value }<0,05) \text {, } \\
\text { sehingga dapat disimpulkan bahwa ada }\end{array}$} & & \multicolumn{4}{|c|}{$\begin{array}{l}31 \text { responden }(72,1 \%) \text {, dan yang memiliki } \\
\text { personal hygiene kurang baik sebanyak } 12 \\
\text { responden }(27,9 \%) \text {, sedangkan responden } \\
\text { dengan status social ekonomi kurang dan } \\
\text { memiliki personal hygiene baik yaitu } \\
\text { sebanyak } 16 \text { responden }(28,1 \%) \text {, dan yang } \\
\text { memiliki personal hygiene kurang baik } \\
\text { yaitu sebanyak } 41 \text { responden }(71,9 \%) \text {. } \\
\text { Berdasarkan dari hasil uji Chi-square } \\
\text { dengan } \rho \text { value }=0,000 \text { ( } \rho \text { value }<0,05) \text {, } \\
\text { sehingga dapat disimpulkan bahwa ada } \\
\text { hubungan yang bermakna status social } \\
\text { ekonomi dengan personal hygiene remaja } \\
\text { responden di SMA Negeri } 1 \text { Kotamobagu. }\end{array}$} \\
\hline
\end{tabular}

hubungan yang bermakna pengetahuan dengan personal hygiene remaja responden di SMA Negeri 1 Kotamobagu.

Menunjukkan bahwa responden dengan status social ekonomi cukup dan memiliki personal hygiene baik sebanyak

\section{PEMBAHASAN}

Pengetahuan tentang hygiene akan mempengaruhi praktik personal hygiene. Namun, hal ini saja tidak cukup, karena motivasi merupakan kunci penting dalam pelaksanaan 
hygiene tersebut. Permasalahan yang sering terjadi adalah ketiadaan motivasi karena kurangnya pengetahuan (Isron Laily., 2012). Hasil penelitian ini didapatkan bahwa terdapat hubungan yang bermakna pengetahuan dengan personal hygiene pada remaja responden di SMA Negeri 1 Kotamobagu. Hal ini disebabkan karena masih banyak siswa pada saat diwawancarai mereka masih kurang paham mengenai personal hygiene pada organ reproduksi.

Hasil penelitian ini sejalan dengan (Ayatullah, 2014) yang menyatakan hasil uji statistic Fisher Exact diperoleh nilai $p=0,008$. Dengan demikian Ho ditolak Ha diterima atau ada hubungan antara tingkat pengetahuan remaja putrid dengan personal hygiene. Selain itu juga sejalan dengan penelitian (Bujawati et al., 2017) berdasarkan hasil analisis hubungan antara pengetahuan tentang menstruasi dengan personal hygiene selama menstruasi menggunakan analisis Chi-square di peroleh nilai $p=0,000$ $(\mathrm{p}<0,05)$ yang berarti bahwa pengetahuan tentang menstruasi memiliki hubungan yang signifikan dengan personal hygiene selama menstruasi pada santriwati Madrasah Aliyah di Pondok Pesantren babul Khaer.

Teori (Patricia, 2005)bahwa dalam personal hygiene terdapat faktor yang berpengaruh diantaranya pengetahuan yang dimiliki oleh individu tersebut. Pengetahuan yang dimaksudkan merupakan pengetahuan yang bersangkutan dengan personal hygiene diantaranya pengetahuan tentang menstruasi, pengetahuan kesehatan reproduksi pada wanita dan pengetahuan mengenai kebersihan diri pada wanita baik saat menstruasi maupun dalam keseharian. Ada banyak faktor yang berpengaruh terhadap pengetahuan, menurut (Notoatmodjo, 2011), tingkat pengetahuan seseorang dipengaruhi oleh tingkat pendidikan, pengalaman, usia, informasi, lingkungan budaya dan social ekonomi.

Kesehatan organ reproduksi penting untuk dijaga agar fertilitas tetap terjaga sehingga mampu menghasilkan keturunan. Saat menstruasi tubuh cenderung memproduksi lebih banyak keringat, minyak dan cairan tubuh lainnya. Sehingga seorang wanita harus tetap menjaga kebersihan dirinya
Terutama menjaga organ reproduksi wanita yaitu kesehatan vagina (Kusmiran, 2012). Bagian tubuh yang tertutup dan lipatan-lipatan kulit seperti di daerah alat kelamin merupakan bagian yang paling penting. Ketika tubuh mengeluarkan banyak keringat maka bagian ini cenderung lembab dan mikroorganisme jahat seperti jamur mudah berkembang biak yang akhirnya dapat menimbulkan infeksi. Hal ini ditunjukkan oleh banyaknya wanita yang mengalami keputihan dan gatal-gatal di vagina akibat adanya infeksi jamur dan bakteri (Pudiastuti, 2012).

Status

sosialekonomiseseorangmempengaruhijenis dan tingkatpraktikpersonal hygiene. Status ekonomi yang rendahmemungkinkanpersonal hygiene yang rendahpula. Kepercayaan (kebudayaan) nilai pribadi akan mempengaruhi perawatan personal hygiene. Berbagai budaya memiliki praktik hygiene yang berbeda (Isro'in Laily., 2011). Hasil penelitian ini didapatkan bahwa terdapat hubungan yang bermakna status social ekonomi dengan personal hygiene pada remaja responden di SMA Negeri 1 Kotamobagu. Hal ini disebabkan bahwa status social ekonomi yang tinggi mempengaruhi personal hygiene dan status social ekonomi yang rendah pula tidak mempengaruhi personal hygiene seseorang. Pendapatan tidak selamanya akan mempengaruhi gaya hidup seseorang, sebab bahan dan alat begitu mudah untuk didapatkan. Orang tua atau keluarga yang mempunyai status social ekonomi yang rendah atau pendapat yang tinggi sama-sama akan mempraktikan gaya hidup yang sehat, meskipun ada perbedaan hygiene. Orang tua yang mampu secara financial dapat mendukung remaja putrid dalam melakukan personal hygiene, namun tidak semua responden merasa bahwa pendapatan orang tua merupakan faktor yang dapat mempengaruhi mereka dalam melakukan personal hygiene.

Penelitian ini sejalan dengan penelitian (Dolang et al., 2013), dimana diperoleh nilai $p=0,000$, karena nilai $\mathrm{p}<0,05$ maka Ho ditolak dan Ha diterima. Artinya ada hubungan antara status social ekonomi keluarga dengan praktik hygiene menstruasi. Hal ini juga sejalan dengan teori (Suparyanto, 2010) status social ekonomi adalah kedudukan atau posisi seseorang dalam 
masyarakat, status social ekonomi adalah gambaran tentang keadaan seseorang atau suatu masyarakat yang ditinjau dari segi social ekonomi, gambaran itu seperti tingkat pendidikan, pendapatan, dan sebagainya. Status ekonomi kemungkinan besar merupakan pembentuk gaya hidup keluarga. Pendapatan keluarga memadai akan menunjang tumbuh kembang anak. Karena orang tua dapat menyediakan semua kebutuhan anak baik primer maupun sekunder. Status ekonomi adalah kedudukan seseorang atau keluarga di masyarakat berdasarkan pendapatan per bulan. Status ekonomi dapat dilihat dari pendapatan yang disesuaikan dengan harga barang pokok.

\section{KESIMPULAN DAN SARAN}

Pengetahuan dan status social ekonomi merupakan faktor yang berhubungan dengan personal hygiene pada remaja putri di SMA Negeri 1 Kotamobagu. Disarankan agar di sekolah harus mengadakan penyuluhan mengenai personal hygiene dan kesehatan reproduksi pada remaja khususnya terkait personal hygiene pada remaja putri.

\section{DAFTAR PUSTAKA}

Atsani, K. A. (2012). Hubungan Peran Ibu Dengan Perlaku Vulvs Hygine Saat Menstruasi Pada Responden SMP Negeri 1 Pleret Bantul Yogyakarta. Sekolah Tinggi Ilmu Kesehatan Aisyiyah Yogyakarta.

Ayatullah. (2014). Faktor yang berhubungan dengan personal hygiene pada remaja putri di SMA Cokroaminoto Makassar. STIKES YAHYA BIMA.

Baker, K. K., Padhi, B., Torondel, B., Das, P., Dutta, A., Sahoo, K. C., Das, B., Dreibelbis, R., Caruso, B., Freeman, M. C., Sager, L., \& Panigrahi, P. (2017). From menarche to menopause: A populationbased assessment of water, sanitation, and hygiene risk factors for reproductive tract infection symptoms over life stages in rural girls and women in India. PLoS ONE, 12(12), 1-20. https://doi.org/10.1371/journal.pone.01882 34

Bujawati, E., Raodhah, S., \& Indriyanti, I. (2017). Faktor-Faktor Yang Berhubungan dengan Personal Hygiene Selama
Menstruasi pada Santriwati di Pesantren Babul Khaer Kabupaten Bulukumba, Provinsi Sulawesi Selatan Tahun 2016. HIGIENE: Jurnal Kesehatan Lingkungan, 3(1), 1-9.

Dolang, M. W., Rahma, \& Ikhsan, M. (2013). Faktor Yang Berhubungan Dengan Praktik Hygiene Menstruasi Pada Responden SMA Negeri 1 Sesean Kabupaten Toraja Utara Factors Related to Menstrual Hygiene Practices of SMA Negeri 1 Sesean Students, North Toraja Regency. Jurnal MKMI, 36-44.

Isro'in Laily., S. A. (2011). Tips Praktis Mengetahui Masa Subur. Katahati.

Isron Laily., S. A. (2012). Personal Hygiene. Graha Ilmu.

Katarina Canggih Pythagoras. (2017). Personal Hygiene Remaja Putri Ketika Menstruasi. Jurnal Promkes: The Indonesian Journal of Health Promotion and Health Education, $\quad 5(1), \quad 12-24$. https://doi.org/10.1007/978-3-319-937014_44

Kusmiran, E. (2012). Kesehatan Reproduksi Remaja dan Wanita. Salemba Medika.

Lavenia, C., \& Dyasti, J. A. (2019). Studi Komparatif Personal Hygiene Mahasiswa Universitas Indonesia di Indekos dan Asrama. Jurnal KSM Eka PRasetya UI, 1(4).

Nadesul, H. (2008). Cantik, Sehat, dan Feminim, Kesehatan Perempuan Sepanjang Usia. PT Kompas Media Nusantara.

Notoatmodjo, S. (2011). Kesehatan Masyarakat Ilmu dan Seni. Rineka Cipta.

Pamaruntuan, A. T. C., Ratag, B. T., \& Rattu, J. A. M. (2014). Hubungan Antara Pengetahuan Tentang Keputihan Dan Higiene Perorangan Dengan Kejadian Keputihan Patologis Pada Responden Sekolah Menengah Atas Negeri 4 Manado. Jurnal Kesehatan Masyarakat, 11-17.

Patricia. (2005). Buku Ajar fundamental Keperawatan Konsep Edisi 4. EGC.

Pudiastuti, R. D. (2012). 3 Fase Penting pada Wanita (Menarche, Menstruasi, dan Menopause).

Suparyanto. (2010). Komponen Dasar Status Ekonom.

Tulus, C. W. K., Kundre, R., \& Bataha, Y. 
(2014). Hubungan Pengetahuan Dan Perilaku Dengan Terjadinya Keputihan Pada Remaja Putri Kelas Xi Di Sma Kristen 1 Tomohon. Jurnal Keperawatan UNSRAT, 2(2).

Wahyudi, A. setiya, Asmoro, C. P., \& Suarilah, I. (2018). Faktor yang Berhubungan dengan Personal Hygiene Saat Menstruasi. Jurnal Kesehatan Manarang, 4(2), 104113. 